\title{
"Leverage constraints or preference for lottery: What explains the low-risk effect in India?"
}

\begin{tabular}{ll} 
AUTHORS & $\begin{array}{l}\text { Shilpa Peswani (iD } \\
\text { Mayank Joshipura (D) }\end{array}$ \\
& $\begin{array}{l}\text { Shilpa Peswani and Mayank Joshipura (2021). Leverage constraints or } \\
\text { preference for lottery: What explains the low-risk effect in India?. Investment } \\
\text { Management and Financial Innovations, 18(2), 48-63. } \\
\text { doi:10.21511/imfi.18(2).2021.05 }\end{array}$ \\
\hline ARTICLE INFO & http://dx.doi.org/10.21511/imfi.18(2).2021.05 \\
\hline DOI & Friday, 16 April 2021 \\
\hline RELEASED ON & Wednesday, 06 January 2021 \\
\hline RECEIVED ON & Friday, 09 April 2021 \\
\hline ACCEPTED ON & \begin{tabular}{l}
$(c c)$ EY \\
\hline LICENSE
\end{tabular} \\
\hline This work is licensed under a Creative Commons Attribution 4.0 International \\
\hline JOURNAL & "Investment Management and Financial Innovations" \\
\hline ISSN PRINT & $1810-4967$ \\
\hline ISSN ONLINE & $1812-9358$ \\
\hline PUBLISHER & LLC “Consulting Publishing Company “Business Perspectives" \\
\hline FOUNDER & LLC “Consulting Publishing Company “Business Perspectives" \\
\hline
\end{tabular}

NUMBER OF REFERENCES

24

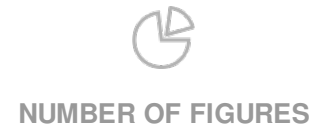

1
NUMBER OF TABLES

13

(C) The author(s) 2021. This publication is an open access article. 


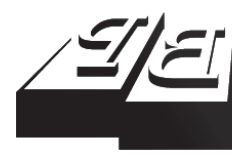

\section{BUSINESS PERSPECTIVES}

LLC "CPC "Business Perspectives" Hryhorii Skovoroda lane, 10, Sumy, 40022, Ukraine www.businessperspectives.org
Received on: $6^{\text {th }}$ of January, 2021 Accepted on: $9^{\text {th }}$ of April, 2021 Published on: $16^{\text {th }}$ of April, 2021

(c) Shilpa Peswani,

Mayank Joshipura, 2021

Shilpa Peswani, Cost Accountant, Programme Head - MBA, and Assistant Professor, St. Francis Institute of Management and Research, Doctoral student -School of Business Management, NMIMS University, Mumbai, India. (Corresponding author)

Mayank Joshipura, Ph.D., Associate Dean- Research and Professor, Schoo of Business Management, NMIMS University, Mumbai, India.

\section{LEVERAGE CONSTRAINTS OR PREFERENCE FOR LOTTERY: WHAT EXPLAINS THE LOW-RISK EFFECT IN INDIA?}

\begin{abstract}
The study empirically investigates two theories that claim to explain the low-risk effect in Indian equity markets using a universe of stocks listed on the National Stock Exchange of India (NSE) from January 2000 to September 2018. Leverage constraints and preference for lottery are two major competing theories that explain the presence and persistence of the low-risk effect. While the leverage constraints theory argues that systematic risk drives low-risk anomaly and therefore risk should be measured using beta, lottery demand theory claims that irrational investor's preference towards stocks with lottery-like payoffs is responsible for the persistence of the low-risk effect, and risk should be measured by idiosyncratic volatility. However, given that most of the risk measures are highly correlated, it is not easy to precisely measure a specific theory's contribution to explaining the low-risk effect. The study constructs the Betting against correlation (BAC) factor to measure the contribution of leverage constraints to the low-risk effect. It further constructs the SMAX factor to untangle the contribution of lottery preference theory. The results show that leverage constraints theory predominantly explains the low-risk effect in Indian markets. This study contributes significantly to the body of literature, as this is the first such study on the Indian market, one of the major emerging markets, especially when the debate on theories explaining the low-risk effect is yet to settle.
\end{abstract}

\section{Keywords betting against beta $(\mathrm{BAB})$, betting against correlation (BAC), MAX, asset pricing, low-risk anomaly, beta, idiosyncratic volatility, skewness of returns}

\section{JEL Classification G11, G12, G14}

\section{INTRODUCTION}

The Capital Asset Pricing Model (CAPM) predicts a positive relationship between an investment's risk and its estimated return. However, in their early tests of the CAPM, Black et al. (1972) report a flat relationship between risk and return in the equity markets. Haugen and Heins (1975) report an inverse relationship between the stock return and its volatility. The portfolio of less risky stocks delivers positive alpha, namely, the 'low-risk effect'. The low-risk effect persists over several years despite investors wanting to earn higher returns at a lower risk. It is prevalent across developed and emerging markets and within various asset classes. The mounting empirical evidence for the presence of low-risk anomaly and its robustness to different risk measures and market cycles triggered the wave of studies trying to either explain its existence or explain it away. To this end, various competing theories based on market friction, limits to arbitrage, leverage and short-selling constraints and behavioral biases played their part in explaining the persistence of lowrisk anomaly. While no single theory could explain the low-risk anomaly, two alternative theories, leverage constraints (economic explanation) and lottery preference (behavioral explanation), have emerged predominantly. The proponents of leverage constraints theory use beta as a risk 
measure, while the proponents of lottery preference theory use idiosyncratic volatility and skewness of return distribution to capture the low-risk anomaly. Knowing what explains the persistence of the low-risk effect will provide valuable insight into whether the effect will persist or disappear.

Untangling the low-risk effect drivers is not easy as the risk measures (beta and idiosyncratic risk) are closely correlated. To address this issue, Asness et al. (2018) focused on decomposing beta and the MAX variable into its components. They create factors that specifically represent a theory while being unrelated to the alternate theory. They control for the common element of volatility present in beta and MAX to create Betting against Correlation (BAC) and SMAX factors, respectively. BAC captures the influence of leverage constraints theory on the low-risk effect, while Scaled MAX (SMAX) captures the effect of lottery preference theory. Their study focused on the United States and other developed markets, but did not cover any major emerging markets, not India.

India is the fifth largest economy with a vibrant equity market with more than 5,000 stocks listed on two of its major stock exchanges, the Bombay Stock Exchange (BSE) and the NSE. India has been one of the fastest-growing economies globally and has attracted a significant amount of foreign direct investment (FDI) and foreign portfolio investment (FPI) since the opening up of the economy in the early 1990s. At the end of December 2020, the total market capitalization of the Indian market was close to USD 2.5 trillion. Top 100 companies account for close to USD 2 trillion of market capitalization. Foreign portfolio investors' ownership in the top 100 companies stood at 25\% by December 2020, next to promoters (48\%) and much higher than Domestic Institutional Investors (14\%). Indian equity markets remain a preferred emerging market for foreign institutional investors. Hence, understanding whether and how the low-risk effect or any other known factor manifests in Indian markets compared to its developed and other large emerging markets is vital for global and Indian investors' community.

With this objective, the study investigates the following questions:

1) Is the low-risk effect measured by $\mathrm{BAB}$ and $\mathrm{MAX}$ factor present in the Indian equity markets?

2) How strong is the low-risk effect? Could one or more known factors such as size, value, and shortterm reversal explain it?

3) Betting against Correlation (BAC) vs Betting against Volatility (BAV), which factor explains the BAB?

4) Which theory explains the low-risk effect in India - leverage constraints or lottery preference?

The study finds evidence of the low-risk effect in the Indian equity market using a universe of stocks listed on India's National Stock Exchange (NSE) from January 2000 to September 2018. The effect is unique, and none of the established factors can explain it entirely. It delivers positive risk-adjusted returns irrespective of the risk measure used to create the low-risk factor (BAB or MAX). However, among the lowrisk factors, the factor representing the leverage constraints theory (BAC) outperforms the other lowrisk factors. The factor representing preference for lottery theory delivers negative alpha in the Indian market. The authors believe that such a result may be due to price limits in the Indian market, which controls extreme single-day movement barring a few stocks available for trading in the futures and options market. The theory of leverage constraints dominates in explaining the low-risk effect in India.

The rest of the paper is organized as follows: Section 1 consists of the literature review, section 2 presents the data and the empirical model, section 3 presents the results and discussions, and the last section provides the conclusion.

1 Source: BSE and NSE Websites and CMIE's Prowess corporate database 


\section{LITERATURE REVIEW}

Modern Portfolio Theory (Markowitz, 1952) and CAPM (Sharpe, 1964) establish a positive relationship between systematic risk and expected return; early empirical evidence from Black et al. (1972) observe a flatter than the expected relationship between systematic risk and return. Black (1972) offers leverage constraints as an explanation for a flatter than expected risk-return relationship. Black (1993) shows that these constraints have further tightened over the years. By constructing the $\mathrm{BAB}$ factor, Frazzini and Pedersen (2014) further extend the leverage constraint argument in explaining the excess return of the low-risk effect. They also find that when leverage constraints tighten, the return to the BAB factor is low. Systematic risk (beta) as an explanatory variable of the low-risk effect has survived decades of out-of-sample tests.

The leverage constraints theory is relatively uncomplicated, for instance, an investor, ideally, should allocate funds between an optimum risky portfolio offering the highest reward-to-risk ratio and a risk-free asset and either lend or borrow funds depending on his risk appetite. Investors with high expected returns would borrow funds at a risk-free rate and apply leverage to earn a higher return. However, such an ideal world does not exist. Different markets have different constraints. First, borrowing rates are always higher than lending rates, and therefore capital allocation using leverage comes with a lower reward to risk ratio. Second, in a market such as India, regulations do not allow large institutional investors, such as mutual funds, to use leverage for investing. Such long-only constraints are prevalent in most developed and emerging markets, and hence these leverage constrained investors seeking higher return have no choice but to overweight high-risk stocks and underweight low-risk stocks in their portfolio. It leads to overpricing of high-risk stocks, while low-risk stocks remain underpriced and eventually results in underperformance of high-risk stocks and outperformance of low-risk stocks in the subsequent period.

On the other hand, Ang et al. $(2006,2009)$ show that a portfolio of stocks with low idiosyncratic volatility (IDVOL) delivers high returns, and vice versa. Barberis and Huang (2008) and Brunnermeier et al. (2007) observe that positively skewed security can be overpriced and can earn a negative average excess return. On the same premise, Bali et al. (2011) develop the MAX factor, where MAX is defined as the maximum return earned by stock over the previous month. They show that low MAX stocks' portfolios earn high risk-adjusted returns and explain the negative relation between IDVOL and returns, as shown by Ang et al. (2009). They interpret their findings in the context of a market with poorly diversified yet risk-averse investors who prefer lottery-like assets. Bali et al. (2017) find that IDVOL drives the low-risk effect more than beta. They show that investors' demand for lottery-like stocks is an essential driver of the beta anomaly. The beta anomaly disappears when the beta-sorted portfolio is controlled for the lottery demand factor.

Investors across the world have shown a preference for lottery-like payoffs. While a mathematician would never buy a lottery, given its expected negative payoff, the small probability of winning a big jackpot attracts a herd of people to buy the lottery regularly. In the world of equities, small ticket size, weak fundamental stocks with a small probability of turning around attract investors. They invest in these stocks with an expectation to quickly make some money. It is not limited to small stocks only but generally valid for stocks with high idiosyncratic risk or a recent big positive price move. Such irrational preferences of investors result in overpriced lottery-like stocks and their inferior returns in the subsequent periods.

Further, Baker et al. (2011) state that some part of the low-beta, low-volatility anomaly can be explained by institutional investors' mandates to outperform the benchmark index, which discourages arbitrage activity in stocks. Stambaugh et al. (2015) state that the return - IDVOL relationship is negative among overpriced stocks driven by arbitrage asymmetry with arbitrage risk represented by IDVOL. Liu et al. (2018) show a positive correlation between beta and IDVOL. They show that the low-risk effect is present only in overpriced stocks, and IDVOL drives the effect. Either controlling for IDVOL or excluding overpriced stocks with high IDVOL renders the beta anomaly insignificant. To validate these findings, Asness et al. (2018) examine the alpha of portfolios double 
sorted on mispricing and beta. They show that stock mispricing explains some portion of the low-risk effect but not the full effect. As all these measures of risk are closely related, Asness et al. (2018) rightly state that the most creditable method of distinguishing the theories explaining the low-risk effect is to construct factors that capture one theory while simultaneously being unrelated to the alternate theory.

Developed markets are different from emerging markets, and hence factor returns differ within and across the markets. Factor returns from Kenneth French data library offer the evidence for that. It displays the returns from portfolios defined on three, four and five Fama-French factors ${ }^{2}$. They compute the factor returns for developed markets and emerging markets separately. Emerging markets are different from the developed markets in terms of the number of companies listed on the exchanges, their total market capitalization (size), the composition of large-cap, mid-cap and smallcap stocks, liquidity, turnover, volume, market participants - institutional and individuals, and the risk of continually changing macroeconomic environment. Therefore, one cannot extrapolate the observation of a developed market to an emerging market.

Indian market is an important emerging market given its growing economy, sophisticated trading platforms and well-developed large equity markets with large Foreign Institutional Investors (FII); it is vital to understand how low-risk effect in India manifests itself in terms of its strength and characteristics, and also what explains the low-risk effect in India.

To this end, following Asness et al. (2018), the study constructs the BAC, BAV, low-MAX (LMAX), and SMAX factors. After that, it performs regression analysis of competing for low-risk factors to understand the theory that dominates in explaining India's low-risk effect as none of the studies has constructed and analyzed these factors in an emerging market.

The study contributes to the literature in at least four ways: First, it constructs and analyzes $\mathrm{BAB}$ and MAX portfolios' performance in the Indian equity market and offers strong evidence of the low-risk effect over multiple market cycles. Lowbeta portfolios, the BAB factor and the least MAX portfolios deliver positive risk-adjusted returns. Second, the study decomposes the BAB into BAC and Betting Against Volatility (BAV) factors (following Asness et al., 2018), reports and analyzes their performance and relative strength. Given that there is no Indian evidence to this new way of decomposing $\mathrm{BAB}$, the study offers first-ever evidence in this regard. It finds that both these factors contribute to the $\mathrm{BAB}$ factor, and $\mathrm{BAC}$ has similar characteristics to $\mathrm{BAB}$ and supports the theory of leverage constraints. Novy-Marx and Velikov (2018) show that the BAB returns are driven by the non-standard process adopted to construct the portfolios. To ensure that the results are not driven by the portfolio construction method, the study computes factor returns using an alternate method. However, changing the portfolio construction method does not impact the BAB and BAC factors' robust returns.

Third, the study analyzes the returns earned by the MAX factor while controlling for volatility (i.e. the SMAX factor) and thus studies the contribution of skewness of returns to the low-risk effect. It finds that the SMAX factor (which represents the preference for lottery theory) delivers negative alpha in the Indian market. Changing the factor's turnover period from one month to twelve months does not change its return, nor its relationship with other low-risk factors. It may be due to the presence of daily price limits in the Indian market, which caps significant single-day movement for most stocks except for the small number of stocks for which derivative contracts are available. Fourth, the study performs regression analysis of all the competing factors to understand the dominant factor that explains the low-risk effect in the Indian equity market. It finds that BAC outperforms other factors. Thus, the theory of leverage constraints dominates in explaining India's low-risk effect. SMAX factor delivers insignificant alpha, and hence the preference for lottery theory weakly explains India's low-risk effect.

This study offers critical insight into how individ-

2 Access factor returns of developed and emerging markets by Kenneth French at https://mba.tuck.dartmouth.edu/pages/faculty/ken. french/data_library.html 
ual and institutional investors can construct and execute their low-risk investment strategies to maximize their potential and earn high risk-adjusted returns.

\section{DATA AND EMPIRICAL MODEL}

The study covered a total of 2,976 individual stocks listed on the NSE from January 2000 to September 2018. The number of stocks varies between 732 and 1,398 across the study period, given the stock selection criteria. Figure 1 provides the descriptive statistics.

The NSE is a leading stock exchange in India. In January 2020, NSE's market capitalization was approximately USD 2069 billion, with an average daily turnover of USD 4.7 billion $^{3}$ and 2,354 securities traded on the exchange. The World Federation of Exchanges (WFE) declared NSE as the world's largest derivatives exchange in 2019. NSE emerged as the world's largest stock exchange in 2020 based on the number of contracts traded. NSE is one of the largest and most active stock exchanges in the world.

The stock price ${ }^{\#}$, price-to-book ratio and market capitalization are from the Centre for Monitoring Indian Economy (CMIE) Prowess IQ database.
The excess returns are measured as returns above the 91-day T-bill rate (the risk-free rate, $r f$ ). The risk-free rate is downloaded from India's Reserve bank (RBI) website, and NSE 500 index data is used as a market proxy.

Figure 1 shows the number of stocks included in the sample from Jan-2000 to Sept-2018. The data is sourced from the CMIE Prowess IQ database. The sample stocks are listed on the NSE of India.

The study constructs the $\mathrm{BAB}$ factor following Frazzini and Pedersen (2014), the BAC, BAV, Idiosyncratic risk factor (IVOL), Short term reversal factor (ST_Rev), Total Volatility (TVOL), LMAX and SMAX factors following Asness et al. (2018), and the size (SML) and value (VMG) following Fama and French (1993).

Beta is estimated as in Frazzini and Pedersen (2014), where $\hat{\sigma}_{i}$ and $\hat{\sigma}_{m}$ are the estimated volatility of the stock and the market returns, respectively, and $\hat{\rho}$ is their estimated correlation. Thus, beta is:

$$
\beta_{i}=\hat{\rho}\left(\frac{\hat{\sigma} \mathrm{i}}{\hat{\sigma} \mathrm{m}}\right)
$$

Individual stock's beta is shrunk towards their cross-sectional mean following Vasicek (1973) to account for extreme beta estimates due to biases and noise:

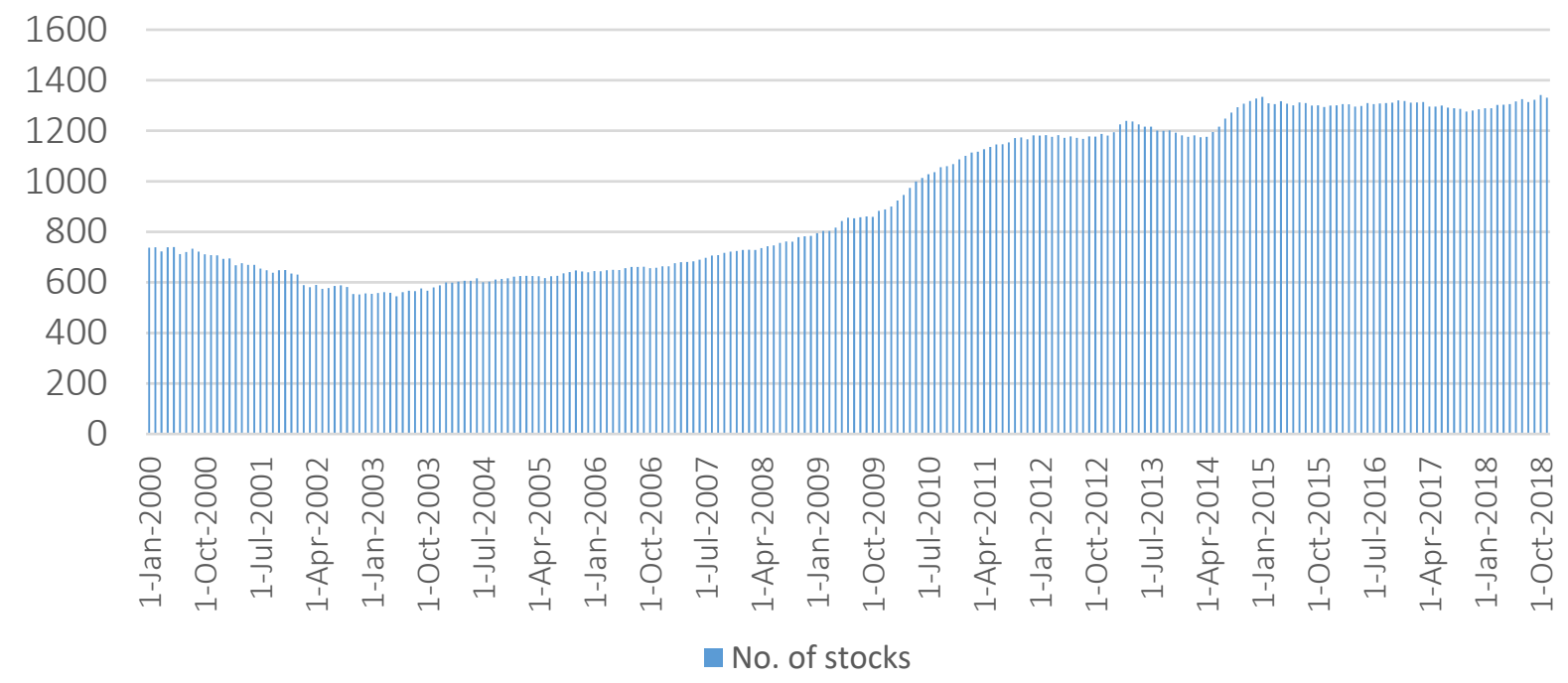

Figure 1. Descriptive statistics

3 USD 1 = INR 75 (rupees) \# The stock's close price is adjusted for dividend, stock split, rights, bonus, and other management actions. 


$$
\hat{\beta}=w_{i} \beta_{i}+\left(1-w_{i}\right) \beta_{m},
$$

where $\hat{\beta}$ is the shrunk beta, $\beta_{i}$ is the stock beta using its time series of returns, $\beta_{m}$ is the market beta, $w_{i}$ and $\left(1-w_{i}\right)>0$, assuming $w_{i}=0.6$ and $\beta_{m}=1$.

The $\mathrm{BAB}$ factor is calculated using equation (3):

$$
B A B=r_{t+1}^{B A B}=\frac{1}{\beta_{t}^{L}}\left(r_{t+1}^{L}-r_{f}\right)-\frac{1}{\beta_{t}^{H}}\left(r_{t+1}^{H}-r_{f}\right) .
$$

The study constructs the BAC factor using the following steps. First, the stocks were sorted based on volatility to create volatility quintile portfolios, and then, within each quintile, it ranks stocks based on their previous month-end correlation with the market to create quintile portfolios. It follows a weighing scheme wherein the stocks with lower correlation have higher weightage in the low-correlation portfolio, and stocks with higher correlations have higher weightage in the high-correlation portfolio. The BAC factor within each volatility quintile portfolio is a longshort portfolio with a long, low-correlation, short high-correlation portfolio. It uses equation (3) to calculate each BAC quintile portfolio return. The overall BAC factor return for a given month is the five BAC factors' simple average as in equation (4).

$$
r_{t+1}^{B A C}=\frac{1}{5} \sum_{q=1}^{5} r_{t+1}^{B A C(q)}
$$

The same method is used to construct the BAV factor. In this case, the stocks are sorted first on their correlation to the market returns, and then within each quintile, rank-based portfolios are created, sorting on the volatility of the stock's returns.

Fama and French (1993) use the median of NYSE-listed stocks as the size break-point to construct the size and value factors. However, this study takes the $90^{\text {th }}$ percentile of total market capitalization as the size break-point for the Indian market (Agarwalla et al., 2013). Every month, the stocks are divided into two size buckets - large-cap bucket (LC) and small-cap bucket (SC). Within each size bucket, the character-specific break-point is the $30^{\text {th }}$ and the $70^{\text {th }}$ percentile. It creates three portfolios within each size bucket. The stocks are value-weighted within a given portfolio.
The character-specific break-point for VMG is the price-to-book ratio, for ST_Rev is a stock's onemonth return, for IVOL is the stock's idiosyncratic risk. Idiosyncratic risk is the residual volatility from the regression of the stock's daily returns over a month and the market returns. The study follows Bali et al. (2011) to construct the MAX variable, where MAX is the average of the five highest daily returns over the previous month. MAXly is the average of the twenty highest daily returns over the previous 12 months. Smax is MAX scaled by the stock's volatility. SMaxly variable is based on volatility-scaled MAX returns over the oneyear look-back period. All the factors related to idiosyncratic risk go long on low-risk stocks and short on high-risk stocks.

\section{RESULTS AND DISCUSSION}

\subsection{Performance of beta-sorted portfolios and the BAB factor}

Table 1 shows excess returns, the CAPM alphas and the three-factor Fama-French model alphas (3F) of the beta-sorted decile portfolios and the $\mathrm{BAB}$ factor. Portfolio risk increases from P1 to P10. The monthly average excess return of $\mathrm{P} 1$ is $1.03 \%$, while that of $\mathrm{P} 10$ is $-0.58 \%$, and their alphas are economically and statistically significant. The Sharpe ratio of P1 (0.69) is higher than that of the market index (0.17). The ex-ante and ex-post betas of the portfolios are nearly the same. The BAB factor's excess return is $1.13 \%$ per month, while alphas are positive and statistically significant. By construction, the ex-ante beta of the BAB portfolio is zero. The ex-post beta is negative. Despite the significant loading on the size factor, the $\mathrm{BAB}$ intercept is very strong. The $\mathrm{BAB}$ factor in India has a tilt towards growth stocks, while in the developed markets, it has a tilt towards value stocks. The Sharpe ratio of $\mathrm{BAB}$ is more than five times that of the market index, while the volatility is comparatively less.

Table 1 reports calendar-time portfolio returns from January 2000 to September 2018. It reports the monthly average excess return, alphas, their t-statistics, ex-ante beta, ex-post beta, volatility, 
Table 1. Performance of beta-sorted portfolios and $B A B$

Source: Author's calculations.

\begin{tabular}{|c|c|c|c|c|c|c|c|c|c|c|c|c|}
\hline $\begin{array}{c}\text { Risk and return } \\
\text { analysis }\end{array}$ & $\begin{array}{c}\text { P1 } \\
\text { (low beta) }\end{array}$ & P2 & P3 & P4 & P5 & P6 & P7 & P8 & P9 & $\begin{array}{c}\text { P } 10 \\
\text { (high beta) }\end{array}$ & BAB & $\begin{array}{c}\text { Nifty } 500 \\
\text { Index }\end{array}$ \\
\hline Excess returns & 1.03 & 0.38 & 0.74 & 0.70 & 0.52 & 0.33 & 0.70 & -0.05 & 0.11 & -0.58 & 1.13 & 0.36 \\
\hline CAPM alpha & 0.82 & 0.14 & 0.52 & 0.43 & 0.23 & 0.07 & 0.40 & -0.32 & -0.13 & -0.76 & 1.26 & - \\
\hline t-stat & 3.48 & 0.59 & 1.88 & 1.66 & 0.97 & 0.26 & 1.58 & -1.19 & -0.38 & -2.00 & 4.28 & - \\
\hline 3F alpha & 0.79 & 0.15 & 0.47 & 0.33 & 0.20 & 0.03 & 0.33 & -0.41 & -0.21 & -0.81 & 1.25 & - \\
\hline t-stat & 3.44 & 0.63 & 1.72 & 1.37 & 0.84 & 0.12 & 1.36 & -1.57 & -0.65 & -2.18 & 4.28 & - \\
\hline Beta (ex-ante) & 0.59 & 0.67 & 0.72 & 0.76 & 0.80 & 0.84 & 0.88 & 0.94 & 1.02 & 1.19 & 0.00 & - \\
\hline Beta (ex-post) & 0.57 & 0.65 & 0.68 & 0.86 & 0.93 & 0.88 & 1.05 & 0.97 & 1.18 & 1.36 & -0.05 & - \\
\hline Volatility & 19.06 & 20.80 & 22.64 & 25.68 & 26.81 & 26.29 & 29.87 & 28.56 & 35.01 & 40.12 & 15.30 & 25.71 \\
\hline Sharpe ratio & 0.69 & 0.22 & 0.41 & 0.34 & 0.24 & 0.15 & 0.29 & -0.02 & 0.04 & -0.17 & 0.95 & 0.17 \\
\hline MKT & 0.56 & 0.66 & 0.65 & 0.78 & 0.90 & 0.85 & 1.00 & 0.91 & 1.11 & 1.32 & -0.06 & - \\
\hline t-stat & 16.69 & 18.95 & 16.40 & 22.61 & 26.28 & 22.51 & 28.33 & 24.31 & 23.35 & 24.70 & -1.38 & - \\
\hline SML & 0.17 & 0.08 & 0.08 & 0.02 & 0.08 & -0.05 & 0.13 & 0.06 & 0.24 & 0.31 & 0.18 & - \\
\hline t-stat & 3.06 & 1.34 & 1.24 & 0.31 & 1.47 & -0.83 & 2.21 & 0.93 & 3.02 & 3.47 & 2.59 & - \\
\hline VMG & -0.08 & -0.09 & 0.06 & 0.26 & 0.03 & 0.14 & 0.07 & 0.19 & 0.04 & -0.10 & -0.12 & - \\
\hline t-stat & -1.50 & -1.64 & 0.94 & 4.71 & 0.46 & 2.35 & 1.26 & 3.23 & 0.58 & -1.20 & -1.82 & - \\
\hline $\mathrm{R}^{2}$ & 0.61 & 0.65 & 0.61 & 0.77 & 0.79 & 0.74 & 0.82 & 0.78 & 0.77 & 0.77 & 0.04 & - \\
\hline
\end{tabular}

Note: Bold indicates $5 \%$ statistical significance.

Sharpe ratios, factor loadings with their t-statistics, and R-squared of beta-sorted portfolios. The stocks are value-weighted within a given portfolio. Column titled BAB reports the same statistics for the $\mathrm{BAB}$ factor. The rightmost column shows the excess market returns. t-statistics are shown below the coefficient estimates.

\subsection{Systematic risk: $B A B, B A C$ and $B A V$}

\subsubsection{Decomposing beta into correlation and volatility}

The study segregates $B A B$ returns into two factors $-\mathrm{BAC}$ and BAV. BAC factor goes long with a low correlation to the market and shorts those with high correlation while seeking to match the bought and sold stocks' volatility. Because stocks with lower market correlation have lower market betas when holding volatility constant, the study expects BAC to behave just like BAB, thus explaining the theory of leverage constraints. BAC, already controlled for volatility, is not closely associated with idiosyncratic volatility. BAV goes long and short based on volatility seeking to match correlation. BAV is closely associated with volatility since it is controlled for correlation.

\subsection{Double sorting by the volatility of stock returns and their correlation with the market index}

Before constructing the BAC and BAV, the study double sorts the stocks to analyze the returns from one variable while controlling for the other. Table 2 shows the results of these $5 \times 5$ quintile portfolios, first sorted on stock's volatility and then sorted on the stock's correlation to the market. Portfolio P1 consists of stocks with the lowest volatility and correlation, and as one progresses to portfolio $\mathrm{P} 5$, the correlation increases. Similarly, as one progresses from portfolio A to E, volatility increases. The theory of leverage constraints suggests that stocks with high betas have low alphas. The high beta of these stocks indicates their high correlation with the market. According to the theory of leverage constraints, stocks with a higher correlation to the market should have high beta and deliver lower alphas. Panel B of Table 2 displays the risk-adjusted returns of the portfolios. In most of the observations, the $3 \mathrm{~F}$ alpha decreases with an increase in volatility and correlation. The $3 \mathrm{~F}$ alpha of $\mathrm{P} 1 \mathrm{~A}$ is $0.87 \%$, while that of $\mathrm{P} 5 \mathrm{E}$ is $-1.72 \%$. Both are statistically significant. Panel A reports ex-post betas of these portfolios. Beta tends to increase with an increase in volatility and correlation. It is essential to this study as one needs to know 
whether ex-ante estimates predict ex-post measures of risk. As seen in Panel A, ex-post CAPM beta does increase with both ex-ante volatility and correlation. It implies that arranging stocks on their ex-ante volatility and correlation also arranges them on ex-post beta and a stock's correlation to the market.

Table 2. Correlation vs volatility: Risk-adjusted returns and beta

Source: Author's calculations.

Panel A. CAPM beta

\begin{tabular}{|c|c|c|c|c|c|c|}
\hline \multicolumn{7}{|c|}{ Conditional sort on the correlation } \\
\hline \multirow{6}{*}{ 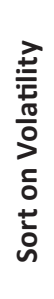 } & Risk analysis & P1 (low) & P2 & P3 & P4 & P5 (high) \\
\hline & A (low) & 0.61 & 0.88 & 1.00 & 1.33 & 1.29 \\
\hline & B & 0.61 & 0.94 & 1.07 & 1.20 & 1.38 \\
\hline & C & 0.67 & 0.96 & 1.23 & 1.45 & 1.41 \\
\hline & D & 0.62 & 1.00 & 1.22 & 1.44 & 1.35 \\
\hline & E (high) & 0.77 & 1.05 & 1.26 & 1.54 & 1.66 \\
\hline
\end{tabular}

Panel B. 3F alpha

\begin{tabular}{|c|c|c|c|c|c|c|}
\hline \multicolumn{7}{|c|}{ Conditional sort on the correlation } \\
\hline \multirow{11}{*}{ 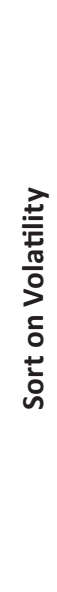 } & $\begin{array}{c}\text { Return } \\
\text { analysis }\end{array}$ & $\begin{array}{c}\text { P1 } \\
\text { (low) }\end{array}$ & P2 & P3 & P4 & $\begin{array}{c}\text { P5 } \\
\text { (high) }\end{array}$ \\
\hline & A (low) & 0.87 & 0.04 & 0.92 & -0.50 & -0.52 \\
\hline & t-stat & 3.68 & 0.12 & 2.09 & -0.89 & -0.74 \\
\hline & B & 0.49 & 0.37 & 0.35 & -0.84 & 0.24 \\
\hline & t-stat & 1.72 & 1.16 & 1.02 & -1.71 & 0.34 \\
\hline & C & 0.27 & 0.12 & 1.00 & -0.44 & -0.56 \\
\hline & t-stat & 0.94 & 0.39 & 2.55 & -1.15 & -1.11 \\
\hline & D & 0.24 & 0.52 & -0.10 & -0.58 & -0.96 \\
\hline & t-stat & 0.98 & 1.68 & -0.31 & -1.49 & -1.46 \\
\hline & E (high) & 0.06 & -0.14 & -0.76 & -0.70 & -1.72 \\
\hline & t-stat & 0.41 & -0.53 & -2.22 & -1.75 & -3.31 \\
\hline
\end{tabular}

Note: Bold indicates $5 \%$ statistical significance.

Table 2 reports the properties of portfolios of stocks sorted first on the stock's volatility and then within volatility quintile re-sorted on the stock's correlation with the MKT. Panel A reports the CAPM beta. Panel B reports the three-factor alphas. Alphas are monthly percent, and t-statistics are below the coefficient estimates.

\subsubsection{Interaction of $B A B$ with its components: $B A C$ and $B A V$}

The study analyzes the extent of each long-short factor's contribution to decompose the $\mathrm{BAB}$ fac- tor - BAC and BAV. Table 3, Panel A, reports the correlation of $\mathrm{BAB}, \mathrm{BAC}$, and $\mathrm{BAV}$. $\mathrm{BAB}$ is more correlated with BAC than BAV. Also, BAC and BAV are negatively correlated. Table 3, Panel B, displays a regression of the $\mathrm{BAB}$ factor on the $\mathrm{BAC}$ factor and the BAV factor. It shows that both BAC and $\mathrm{BAV}$ play a role in delivering returns to the $\mathrm{BAB}$ factor. The regression coefficient of $\mathrm{BAC}$ on $\mathrm{BAB}$ is 0.74 and on BAV is 0.58 . The R-squared of the regression is $86 \%$, while the intercept is zero. The two components very well explain the $\mathrm{BAB}$ factor.

Table 3. Disintegrating BAB into its components: The BAC and BAV factors

Source: Author's calculations.

Panel A. Correlation

\begin{tabular}{c|c|c|c}
\hline & BAB & BAC & BAV \\
\hline BAB & 1 & - & - \\
\hline BAC & 0.62 & 1 & - \\
\hline BAV & 0.37 & -0.43 & 1 \\
\hline
\end{tabular}

Panel B. Regression

\begin{tabular}{l|c}
\hline \multicolumn{1}{c|}{ Key metrics } & BAB \\
\hline Intercept & 0.00 \\
\hdashline t-stat & -1.77 \\
\hdashline BAC & $\mathbf{0 . 7 4}$ \\
\hline t-stat & 34.51 \\
\hline BAV & $\mathbf{0 . 5 8}$ \\
\hline t-stat & 28.08 \\
\hline R & 0.86 \\
\hline
\end{tabular}

Note: Bold indicates 5\% statistical significance.

Table 3 reports the result of the correlation of $B A B$, $\mathrm{BAC}$ and the BAV factors in Panel A. It also reports the result of a regression of the $\mathrm{BAB}$ factor on the BAC and the BAV factors in Panel B. t-statistics are shown below the coefficient estimates.

\subsubsection{Performance and coefficients of BAC and BAV}

Further, the study analyzes the performance of the $\mathrm{BAC}$ and the BAV factors exclusively. Table 4 reports the returns and the regression coefficients of the BAC factor and its components. The alphas of all the BAC quintiles and the main BAC factor are statistically significant, and they weigh heavily on the size factor. The main BAC factor has a negative 
loading on the value factor, just like the $\mathrm{BAB}$ factor in Table 1. BAC significantly correlates with $B A B$ and displays similar characteristics to BAB. As correlation is closely related to systematic risk when controlled for volatility, BAC perfectly represents the BAB factor. Therefore, BAC also captures the theory of leverage constraints explanation for the existence of the low-risk effect, just like the BAB. The $3 \mathrm{~F}$ alpha of the BAC factor is economically and statistically significant, indicating that it is a unique factor, separate from other established factors.

The study also analyzes the BAV factor's performance and its building blocks (see Appendix A Table A1). The noticeable difference between BAC and BAV is in the loading on the size factor. BAV picks large-cap stocks, while BAC picks small stocks, both delivering significant alphas. This observation is consistent with Joshipura and Peswani's (2017) findings that low-risk portfolios pick large size and growth stocks to deliver high alphas.

Table 4. Betting against correlation (BAC)

Source: Author's calculations.

\begin{tabular}{|c|c|c|c|c|c|c|}
\hline $\begin{array}{c}\text { Return } \\
\text { analysis }\end{array}$ & BAC 1 & BAC 2 & BAC 3 & BAC 4 & BAC 5 & BAC \\
\hline Excess returns & 0.63 & 0.64 & 1.19 & 1.14 & 1.88 & 1.20 \\
\hline CAPM alpha & 0.74 & 0.73 & 1.21 & 1.34 & 2.28 & 1.26 \\
\hline t-stat & 2.61 & 1.97 & 3.16 & 2.62 & 3.01 & 3.40 \\
\hline MKT & -0.03 & 0.09 & 0.24 & 0.15 & 0.27 & 0.14 \\
\hline t-stat & -0.88 & 1.90 & 4.58 & 2.19 & 2.65 & 2.88 \\
\hline Ex-post beta & -0.03 & 0.09 & 0.24 & 0.15 & 0.27 & 0.14 \\
\hline$R^{2}$ & 0.00 & 0.02 & 0.09 & 0.02 & 0.03 & 0.04 \\
\hline Sharpe ratio & 0.53 & 0.41 & 0.74 & 0.55 & 0.64 & 0.79 \\
\hline 3F alpha & 0.64 & 0.50 & 0.93 & 0.89 & 1.49 & 1.13 \\
\hline t-stat & 2.63 & 1.70 & 2.90 & 1.94 & 2.44 & 3.72 \\
\hline MKT & -0.05 & 0.04 & 0.14 & 0.02 & 0.06 & 0.04 \\
\hline t-stat & -1.36 & 0.96 & 3.03 & 0.29 & 0.68 & 1.02 \\
\hline SML & 0.52 & 0.82 & 0.68 & 0.67 & 0.88 & 0.75 \\
\hline t-stat & 8.84 & 11.44 & 8.71 & 6.02 & 5.93 & 10.16 \\
\hline VMG & -0.38 & -0.45 & -0.22 & -0.09 & -0.03 & -0.23 \\
\hline t-stat & -6.83 & -6.66 & -3.00 & -0.89 & -0.23 & -3.28 \\
\hline $\mathrm{R}^{2}$ & 0.28 & 0.38 & 0.33 & 0.19 & 0.21 & 0.36 \\
\hline
\end{tabular}

Note: Bold indicates $5 \%$ statistical significance.

Table 4 reports the BAC factor's performance in each volatility quintile, along with the equal-weighted average of these factors, which is the main BAC factor. Alphas are the intercept in a regression of monthly excess return against the explanatory variables - MKT, SML and VMG. Alphas and Sharpe ratios are reported on a monthly and annualized basis, respectively. $t$-statistics are shown below the coefficient estimates.

\subsection{Unsystematic risk: LMAX, SMAX and IVOL}

\subsubsection{Performance of the MAX factor in the Indian equity market}

Bali et al. (2011) developed the MAX factor to capture the demand for lottery-like payoff stock returns. There is no study on the performance of the MAX factor in the Indian equity market. Therefore, this study examines the performance of the MAX factor in the Indian equity market. Table 5 shows the results of the decile portfolios created by sorting on MAX. P1 comprises stocks with low MAX, while portfolio P10 comprises stocks with the highest MAX. The study observes that the lowest MAX portfolios' monthly average excess return is $0.79 \%$, and its alphas are economical and statistically significant. The ex-post beta and volatility increase from P1 to P10. The Sharpe ratio is highest for P1 and least for P10. These findings reveal that demand for lottery-like payoff stocks may contribute to the low-risk effect in India.

Table 5 shows the returns of the decile portfolios of stocks sorted by MAX. Excess returns of these value-weighted portfolios are over and above the risk-free rate. Alphas are the intercept in a regression of monthly excess return against the explanatory variables - MKT, SML and VMG. Alphas and Sharpe ratios are reported on monthly and annualized basis, respectively. t-statistics are shown below the coefficient estimates.

\subsubsection{Double sorting by the MAX variable and the volatility of stock returns}

A stock can have a high MAX return due to its volatile returns, or its return distribution is positively skewed. To isolate the skewness effect that represents lottery demand, Asness et al. (2018) devised the SMax variable. SMax isolates a stock's realized return distribution and captures the feature of lottery demand. An unconstrained investor seeking 
Table 5. Performance of portfolios sorted by MAX

\begin{tabular}{l|c|c|c|c|c|c|c|c|c|c}
\multicolumn{10}{l|}{ Source: Author's calculations. } \\
\hline Return and risk analysis & P1 & P2 & P3 & P4 & P5 & P6 & P7 & P8 & P9 & P10 \\
\hline Excess returns & 0.79 & 0.36 & 0.14 & -0.18 & 0.21 & 0.44 & 0.42 & -0.10 & 0.17 & -1.06 \\
CAPM alpha & $\mathbf{0 . 5 4}$ & 0.08 & -0.13 & -0.46 & -0.08 & 0.14 & 0.17 & -0.34 & -0.03 & -1.06 \\
t-stat & 2.23 & 0.40 & -0.53 & -1.78 & -0.30 & 0.53 & 0.52 & -0.98 & -0.07 & -1.92 \\
3F alpha & $\mathbf{0 . 4 8}$ & 0.03 & -0.17 & -0.51 & -0.20 & 0.02 & 0.09 & -0.45 & -0.15 & -1.33 \\
t-stat & 2.02 & 0.17 & -0.71 & -2.00 & -0.87 & 0.09 & 0.28 & -1.44 & -0.42 & -3.00 \\
Ex-post beta & 0.71 & 0.79 & 0.87 & 0.92 & 0.96 & 1.09 & 1.23 & 1.27 & 1.44 & 1.30 \\
Volatility & 22.19 & 22.82 & 25.81 & 27.15 & 28.17 & 31.29 & 35.77 & 37.16 & 42.14 & 43.84 \\
Sharpe ratio & 0.45 & 0.19 & 0.07 & -0.08 & 0.09 & 0.17 & 0.15 & -0.03 & 0.05 & -0.27 \\
\hline
\end{tabular}

Note: Bold indicates $5 \%$ statistical significance.

lottery-like returns can apply leverage to build a portfolio of stocks with low volatility and high scaled MAX. Table 6 shows the CAPM alphas of $5 \times 5$ portfolios sorted first on the stock's volatility and later on SMax. The study observes that in the Indian equity market, the alpha of P1A is not statistically significant, nor does it display any performance trend. This observation communicates that MAX gets its return due to the stock's volatility. When controlled for volatility, low SMax delivers a positive but statistically insignificant alpha.

Table 6. Performance of portfolios sorted by SMax and Volatility

\begin{tabular}{|c|c|c|c|c|c|c|}
\hline \multicolumn{7}{|c|}{ Conditional sort on SMAX } \\
\hline \multirow{11}{*}{ 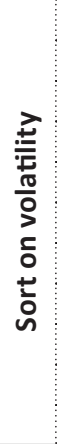 } & & P1 (low) & P2 & P3 & P4 & P5 (high) \\
\hline & A (low) & 0.37 & 0.38 & -0.07 & -0.21 & -0.99 \\
\hline & t-stat & 1.25 & 1.03 & -0.18 & -0.31 & -1.55 \\
\hline & B & 0.40 & -0.70 & -0.17 & -0.71 & -0.09 \\
\hline & t-stat & 1.41 & -2.17 & -0.46 & -1.51 & -0.14 \\
\hline & C & 0.54 & -0.15 & -0.53 & -0.64 & -0.42 \\
\hline & t-stat & 1.81 & -0.44 & -1.41 & -1.41 & -0.72 \\
\hline & D & -0.13 & -0.29 & 0.17 & 0.41 & -1.72 \\
\hline & t-stat & -0.50 & -0.88 & 0.45 & 0.82 & -3.32 \\
\hline & E (high) & 0.18 & 0.21 & 0.39 & 0.07 & -0.29 \\
\hline & t-stat & 0.70 & 0.75 & 1.07 & 0.18 & -0.49 \\
\hline
\end{tabular}

Table 6 reports the CAPM alphas of $5 \times 5$ portfolios sorted first on volatility and later on SMax. Alphas are monthly percent, and t-statistics are below the coefficient estimates.

\subsubsection{Decomposing LMAX into SMAX and TVOL}

The study observed that MAX delivers positive and significant alpha in the Indian stock market. However, the bivariate analysis of volatility and SMax delivers positive but insignificant alphas for P1A. The study further constructs the LMAX fac- tor and analyzes its performance. Although Table 5 suggests that MAX earns its alpha from stock's volatility and skewness of its returns, the study decomposes LMAX factor into SMAX factor and Total Volatility (TVOL) factor. Table 7 shows the result of the regression of LMAX on SMAX and TVOL factors. The study observes that the regression of LMAX on SMAX and TVOL explains 91\% of the relation. Both TVOL and SMAX combine to explain the LMAX factor.

Table 7. LMAX as SMAX and TVOL

Source: Author's calculations

\begin{tabular}{l|c}
\hline \multicolumn{1}{c|}{ Key metrics } & LMAX \\
\hline Intercept & 0.00 \\
\hline t-stat & -1.56 \\
\hline SMAX & $\mathbf{0 . 3 8}$ \\
\hdashline t-stat & 11.76 \\
\hline TVOL & $\mathbf{0 . 8 4}$ \\
\hline t-stat & 46.61 \\
\hline R $^{2}$ & 0.91 \\
\hline
\end{tabular}

Note: Bold indicates $5 \%$ statistical significance.

Table 7 reports the regression results of the LMAX factor on the SMAX and the TVOL factors. t-statistics are shown below the coefficient estimates.

\subsubsection{Performance and factor exposure of IDVOL factors}

Table 8 shows the performance and factor exposure of the idiosyncratic risk factors controlling for the market, size, value, and short-term reversal factors. The study observes that in the Indian equity market, SMAX delivers negative alpha. The SMAX shows substantial factor exposure to shortterm reversal factor (ST_Rev). The controlling factors' explanation power increases from 5\% to $55 \%$ after the inclusion of the ST_Rev factor on the re- 
Table 8. The IDVOL risk factors

Source: Author's calculations.

\begin{tabular}{|c|c|c|c|c|c|c|c|c|c|}
\hline Key metrics & SMAX & SMAX & SMAX & LMAX & LMAX & LMAX & IVOL & IVOL & IVOL \\
\hline Alpha & -0.25 & -0.27 & -0.06 & 0.53 & 0.54 & 0.64 & 0.71 & 0.76 & 0.79 \\
\hline t-stat & -1.17 & -1.22 & -0.41 & 2.04 & 2.11 & 2.64 & 2.81 & 3.14 & 3.25 \\
\hline MKT & 0.10 & 0.09 & 0.06 & -0.44 & -0.44 & -0.45 & -0.47 & -0.44 & -0.44 \\
\hline t-stat & 3.38 & 2.83 & 2.92 & -12.75 & -11.93 & -12.88 & -13.80 & -12.40 & -12.48 \\
\hline SML & - & 0.05 & 0.05 & - & -0.21 & -0.21 & - & -0.28 & -0.28 \\
\hline t-stat & - & 0.90 & 1.35 & - & -3.36 & -3.52 & - & -4.66 & -4.66 \\
\hline VMG & - & 0.00 & -0.01 & - & 0.14 & 0.13 & - & 0.08 & 0.08 \\
\hline t-stat & - & -0.04 & -0.34 & - & 2.39 & 2.42 & - & 1.45 & 1.42 \\
\hline ST_REV & - & - & 0.50 & - & - & 0.25 & - & - & 0.07 \\
\hline t-stat & - & - & 15.69 & - & - & 4.94 & - & - & 1.34 \\
\hline Sharpe ratio & -0.25 & -0.25 & -0.25 & 0.08 & 0.08 & 0.08 & 0.19 & 0.19 & 0.19 \\
\hline$R^{2}$ & 0.05 & 0.05 & 0.55 & 0.42 & 0.45 & 0.51 & 0.46 & 0.51 & 0.52 \\
\hline
\end{tabular}

Note: Bold indicates $5 \%$ statistical significance.

gression's right-hand side. The loading of SMAX and LMAX on ST_Rev is by construction as these factors short stocks with an average of high returns on highest gain days. The IVOL (idiosyncratic volatility) factor has insignificant loading on ST_Rev, and including it on the right-hand side of the regression hardly changes the alpha. The performance of LMAX and IVOL is nearly the same, while the Sharpe ratio of IVOL is higher than the LMAX factor. Both factors pick large-cap value stocks in their portfolios. However, a comprehensive look at the Sharpe ratios of all these factors indicates that they are all low. Thus, SMAX delivers negative alpha among the IDVOL risk factors, but LMAX and IVOL deliver positive and significant alphas.

Table 8 shows alphas and factor loadings of SMAX, LMAX and IVOL factors on the control variables - MKT, SML, VMG and ST_Rev. Alphas and Sharpe ratios are reported on monthly and annualized basis, respectively. t-statistics are shown below the coefficient estimates.

The study also changes the duration over which the characteristics of the idiosyncratic risk factors is estimated. It re-calculates the returns earned by LMAX and SMAX using one-year characteristics of MAX rather than one month to observe any change in results. This exercise is done to have a like-for-like comparison of systematic risk factors and unsystematic risk factors as the duration of the characteristics over which $\mathrm{BAB}$ and $\mathrm{BAC}$ are computed is one to five years, while that of LMAX and SMAX is one month. A high turnover means these factors are more sensitive to microstructure changes and thereby have a high trading cost. Although the study includes ST_Rev factor to capture some of these issues, constructing more stable characteristics-based factors helps in a careful comparison of these factors. However, the study observes that changing MAX variable characteristics does not contribute to the alpha of these factors (see Appendix B Table B1).

\subsection{A performance marathon}

\subsubsection{A performance marathon based on published factors}

The analysis so far shows that the two explanations to the low-risk effect share a common element related to volatility and have a distinct element related to correlation and the skewness of the return distribution. It suggests that in the Indian equity market; the factor representing the theory of leverage constraints (BAC) is more robust than the factor representing the theory of demand for lottery stocks (SMAX). To further gauge the separate power of these factors, the study regresses each systematic and idiosyncratic risk factor on a contending factor along with the $3 \mathrm{~F}$ model and the $\mathrm{ST}_{-}$ Rev factors. Table 9 reports the results. BAB, BAC and BAV have positive and significant alphas even after controlling for the 3F model, ST_Rev, LMAX and IVOL. It communicates that a combination of idiosyncratic risk factors, the $3 \mathrm{~F}$ model, and the ST_Rev factor does not fully explain the low-risk effect. The alpha of $B A C$ is higher than that of $B A B$ and BAV. As BAC, by construction, is less correlat- 
Table 9. Performance marathon among published factors

\begin{tabular}{|c|c|c|c|c|c|c|}
\hline Key metrics & BAB & BAC & BAV & LMAX & SMAX & IVOL \\
\hline Alpha & 0.72 & 0.76 & 0.67 & 0.10 & 0.05 & 0.27 \\
\hline t-stat & 2.90 & 2.58 & 2.42 & 0.47 & 0.29 & 1.24 \\
\hline MKT & 0.25 & 0.22 & 0.05 & -0.43 & 0.06 & -0.42 \\
\hline t-stat & 5.39 & 3.98 & 1.05 & -14.51 & 2.74 & -13.85 \\
\hline SML & 0.34 & 0.85 & -0.43 & -0.29 & 0.07 & -0.36 \\
\hline t-stat & 5.46 & 11.65 & -6.27 & -5.80 & 1.79 & -6.96 \\
\hline VMG & -0.20 & -0.26 & -0.04 & 0.19 & -0.02 & 0.13 \\
\hline t-stat & -3.49 & -3.83 & -0.58 & 4.02 & -0.65 & 2.75 \\
\hline ST_Rev & -0.30 & -0.22 & -0.15 & 0.33 & 0.49 & 0.14 \\
\hline t-stat & -5.10 & -3.21 & -2.30 & 7.55 & 15.14 & 3.22 \\
\hline $\mathrm{BAB}$ & - & - & - & 0.46 & -0.09 & 0.44 \\
\hline t-stat & - & - & - & 9.64 & -2.59 & 9.11 \\
\hline LMAX & 0.46 & 0.03 & 0.41 & - & - & - \\
\hline t-stat & 3.07 & 0.15 & 2.47 & - & - & - \\
\hline IVOL & 0.21 & 0.35 & 0.22 & - & - & - \\
\hline t-stat & 1.44 & 1.98 & 1.30 & - & - & - \\
\hline Sharpe ratio & 0.95 & 0.79 & 0.35 & 0.08 & -0.25 & 0.19 \\
\hline$R^{2}$ & 0.35 & 0.44 & 0.55 & 0.65 & 0.57 & 0.65 \\
\hline
\end{tabular}

Note: Bold indicates $5 \%$ statistical significance.

ed with other factors, it is likely to have a higher alpha. BAC has an insignificant loading on LMAX. Thus, BAC is a unique factor different from idiosyncratic risk factors.

The results in Table 8 suggest that LMAX and IVOL have significant alphas even after controlling for the 3F model and ST_Rev factor. However, in Table 9, when these factors are controlled for $\mathrm{BAB}$, their alphas turn insignificant. These results suggest that $\mathrm{BAB}$ motivates the alpha of these factors. It is not surprising that the SMAX factor's alpha does not change, as it is already negative and insignificant in the Indian market (see Table 8).

Table 9 reports the result of regressing each contending low-risk factor on another, as well as other variables. Alphas and Sharpe ratios are reported on monthly and annualized basis, respectively. $\mathrm{t}$-statistics are shown below the coefficient estimates.

\subsubsection{Constructing all factors using the Fama-French methodology and the rank-weighted methodology}

The study constructs $\mathrm{BAB}, \mathrm{BAC}$ and $\mathrm{BAV}$ factors based on a unique risk-weighted method based on Asness et al. (2018), whereas SML, VMG, LMAX,
SMAX, and IVOL factors are constructed using the Fama and French (1993) method.

The study further constructs all the factors using the Fama-French method and again using the rank-weighted method to have an apple-to-apple comparison. Constructing all the factors using the same portfolio construction method helps observe whether the method of portfolio construction influences the explanation power of the factors and the control variables and whether the results differ significantly. Table 10 shows the results. The study observes that BAB, BAC, and BAV have positive and significant alphas after controlling for the 3F model, ST_Rev and the LMAX1Y factors using the Fama-French method. Thus, it rejects the claim that the beta anomaly disappears when controlled for the lottery demand factor (Bali et al., 2017). Although LMAX1Y strongly explains the $\mathrm{BAB}$ return, $\mathrm{BAC}$ loads comparatively less on LMAX1Y. Along with SMAX and SMAX1Y, the alphas of LMAX, and IVOL turn negative and insignificant on controlling for the $\mathrm{BAB}$ factor.

Table 10 shows the results of regressing competing factors constructed following the Fama and French (1993) methodology. Alphas and Sharpe ratios are reported on monthly and annualized basis, respectively. $t$-statistics are shown below the coefficient estimates. 
Table 10. Performance marathon among factors constructed using the Fama-French method

\begin{tabular}{|c|c|c|c|c|c|c|c|c|c|c|}
\hline & \multicolumn{2}{|c|}{ Source: Author's calculation } \\
\hline Key metrics & BAB & BAB & BAC & BAC & BAV & BAV & LMAX & SMAX & SMAX1Y & IVOL \\
\hline Alpha & 0.86 & 0.45 & 0.64 & 0.51 & 1.04 & 0.66 & 0.13 & 0.00 & -0.40 & 0.31 \\
\hline t-stat & 3.29 & 2.49 & 2.84 & 2.31 & 4.50 & 4.39 & 0.67 & -0.01 & -1.87 & 1.54 \\
\hline MKT & -0.55 & -0.14 & -0.17 & -0.04 & -0.55 & -0.17 & -0.12 & 0.03 & -0.02 & -0.13 \\
\hline t-stat & -14.62 & -3.80 & -5.18 & -0.82 & -16.47 & -5.49 & -3.22 & 0.84 & -0.41 & -3.25 \\
\hline SML & -0.19 & 0.09 & 0.04 & 0.13 & -0.42 & -0.16 & -0.09 & 0.04 & -0.15 & -0.16 \\
\hline t-stat & -3.09 & 1.87 & 0.74 & 2.29 & -7.56 & -4.14 & -1.95 & 0.96 & -2.85 & -3.43 \\
\hline VMG & -0.13 & -0.18 & -0.19 & -0.20 & 0.05 & 0.01 & 0.21 & -0.02 & -0.14 & 0.15 \\
\hline t-stat & -2.21 & -4.30 & -3.64 & -4.05 & 0.90 & 0.20 & 4.96 & -0.60 & -2.88 & 3.42 \\
\hline ST_Rev & -0.18 & -0.12 & -0.21 & -0.19 & 0.02 & 0.08 & 0.36 & 0.49 & 0.19 & 0.17 \\
\hline t-stat & -3.21 & -3.09 & -4.29 & -4.00 & 0.43 & 2.42 & 8.93 & 15.03 & 4.16 & 4.01 \\
\hline $\mathrm{BAB}$ & - & - & - & - & - & - & 0.60 & -0.07 & -0.49 & 0.57 \\
\hline t-stat & - & - & - & - & - & - & 12.46 & -1.79 & -9.12 & 11.24 \\
\hline LMAX1Y & - & 0.72 & & 0.23 & & 0.67 & - & - & - & - \\
\hline t-stat & - & 15.84 & & 4.17 & & 17.62 & - & - & - & - \\
\hline Sharpe ratio & 0.12 & 0.12 & 0.41 & 0.41 & 0.20 & 0.20 & 0.08 & -0.25 & -0.71 & 0.19 \\
\hline$R^{2}$ & 0.63 & 0.83 & 0.29 & 0.34 & 0.69 & 0.87 & 0.71 & 0.56 & 0.48 & 0.69 \\
\hline
\end{tabular}

Note: Bold indicates $5 \%$ statistical significance.

As the Fama-French method makes all its factors size-neutral, the study controls all the rank-weighted factors for size. The results from constructing factors using the rank-weighted method are similar to Table 10, but the alphas of LMAX and IVOL remain robust after controlling for the $\mathrm{BAB}$ fac- tor. The factor primarily constructed to capture the demand for lottery-like payoff again delivers insignificant alpha with or without controlling for BAB (see Appendix C Table C1). It implies that a change in the method of factor construction does not influence the result.

\section{CONCLUSION}

The study concludes that both BAB and MAX factors offer significant alpha adjustments for all major factors, and hence both systematic risk and idiosyncratic risk contribute to the low-risk effect in Indian markets. The returns of these factors are robust even after controlling for established factors like market, size and value. Both BAC and BAV combine to explain the BAB factor. But the characteristics of $B A C$ are similar to $B A B$ and thus it efficiently represents the theory of leverage constraints just like the BAB. It further shows that the BAC has high risk-adjusted returns. Though the low-MAX factor delivers positive returns, when controlled for BAB, the returns turn insignificant. The SMAX factor, constructed to represent the theory of demand for lottery stocks, fails to produce statistically significant returns. Even changing the characteristics of the idiosyncratic risk factors does not contribute to the alpha of these factors. In a performance marathon among the low-risk factors, systematic low-risk factors beat the idiosyncratic low-risk factors. Their performance becomes more pronounced when all the factors are constructed using the same method. The results are in line with Asness et al. (2018), the global sample, and different from the US sample. The theory of leverage constraints is a dominant theory driving the low-risk effect and not the preference for the lottery. Not that Indian market participants do not show a preference for lottery-like payoffs, but stock level daily price limits (called circuit breaker) do not allow extreme daily moves for most stocks, except for a small number of stocks for which derivative contracts are available. Constructing lottery demand factor differently to capture the impact of daily price limits may offer further evidence. The results of this study add further evidence to Asness et al.'s (2018) work, which itself is not conclusive as it offers different evidence of theory explaining the low-risk effect in the US and developed global markets. Thus, the low-risk effect is here to stay in the Indian eq- 
uity market unless regulatory bodies change the mandates for availability of leverage in the hands of investors. Thus, the study confirms that Indian investors face extreme leverage and short-selling constraints like most other markets, and the leverage constraints theory drives the low-risk effect in Indian markets.

\section{AUTHOR CONTRIBUTIONS}

Data curation: Shilpa Peswani, Mayank Joshipura.

Formal analysis: Shilpa Peswani, Mayank Joshipura.

Investigation: Shilpa Peswani, Mayank Joshipura.

Project administration: Shilpa Peswani, Mayank Joshipura.

Resources: Shilpa Peswani, Mayank Joshipura.

Software: Shilpa Peswani, Mayank Joshipura.

Supervision: Shilpa Peswani, Mayank Joshipura.

Validation: Shilpa Peswani, Mayank Joshipura.

Writing - original draft: Shilpa Peswani, Mayank Joshipura.

Writing - review \& editing: Shilpa Peswani, Mayank Joshipura.

\section{REFERENCES}

1. Agarwalla, S., Jacob, J., \& Varma, J. (2013). Four factor model in Indian equities market (Working Paper W.P. No. 2013-09-05). Indian Institute of Management, Ahmedabad. Retrieved from http://www.iimahd.ernet.in/ iffm/ Indian-Fama-French-Momentum/ four-factors-India-90s-onwardsIIM-WP-Version.pdf

2. Ang, A., Hodrick, R., Xing, Y., \& Zhang, X. (2006). The Cross Section of Volatility and Expected Return. Journal of Finance, 61(1), 259-299. https://doi.org/10.1111/ j.1540-6261.2006.00836.x

3. Ang, A., Hodrick, R., Xing, Y., \& Zhang, X. (2009). High Idiosyncratic Volatility and Low Returns: International and Further US Evidence. Journal of Financial Economics, 91(1), 1-23. https://doi. org/10.1016/j.jfineco.2007.12.005

4. Asness, C., Frazzini, A., Gormsen, N. J., \& Pedersen, L. (2018). Betting Against Correlation: Testing Theories of the Low-Risk Effect (CEPR Discussion Paper No. DP12686). Retrieved from https://ssrn.com/ abstract $=3122328$

5. Baker, M., Bradley, B., \& Wurgler, J. (2011). Benchmarks as Limits to Arbitrage: Understanding the Low-Volatility Anomaly. Financial Analysts Journal, 67(1), 40-54. https://doi.org/10.2469/faj.v67.n1.4
6. Bali, T., Brown, S., Murray, S., \& Tang, Y. (2017). A Lottery Demand-Based Explanation of the Beta Anomaly. Journal of Financial and Quantitative Analysis, 52(6), 2369-2397. https://doi. org/10.1017/S0022109017000928

7. Bali, T., Cakici, N., \& Whitelaw, R. (2011). Maxing out: Stocks as lotteries and the cross-section of expected returns. Journal of Financial Economics, 99(2), 427446. https://doi.org/10.1016/j. jineco.2010.08.014

8. Barberis, N., \& Huang, M. (2008). Stocks as lotteries: the implications of probability weighting for security prices. American Economic Review, 98(5), 2066-2100. https://doi. org/10.1257/aer.98.5.2066

9. Black, F. (1972). Capital Market Equilibrium with Restricted Borrowing. Journal of Business, 45(3), 444-455. http://dx.doi. org/10.1086/295472

10. Black, F. (1993). Beta and Return. The Journal of Portfolio Management, 20(1), 74-77. Retrieved from http://sbufaculty. tcu.edu/mann/Fin\%2030233\%20 -\%20F2010/Black_FAJ93.pdf

11. Black, F., Jensen, M., \& Scholes, M (1972). The Capital Asset Pricing Model: Some Empirical Tests. In
M. C. Jensen (Ed.), Studies in the Theory of Capital Markets. New York: Praeger

12. Brunnermeier, M. K., Gollier, C., \& Parker, J. (2007). Optimal Beliefs, Asset Prices, and the Preference for Skewed Returns. American Economic Review, 97(2), 156-165. https:// mitsloan.mit.edu/shared/ods/ documents/?DocumentID $=4172$

13. Centre for Monitoring Indian Economy (CMIE). Prowess IQ. Retrieved from https://prowessiq. cmie.com/

14. Fama, E., \& French, K. (1993). Common risk factors in the returns on stocks and bonds. Journal of Financial Economics, 33(1), 3-56. https:// doi.org/10.1016/0304405X(93)90023-5

15. Frazzini, A., \& Pedersen, L. (2014). Betting against Beta. Journal of Financial Economics, 111(1), 1-25. https://doi.org/10.1016/j.jfineco.2013.10.005

16. Haugen, R., \& Heins, J. (1975). Risk and the Rate of Return on Financial Assets: Some Old Wine in New Bottles. The Journal of Financial and Quantitative Analysis, 10(5), 775-784. https:// doi.org/10.2307/2330270 
17. Liu, J., Stambaugh, R., \& Yuan, Y. (2018). Absolving Beta of Volatility's Effects. Journal of Financial Economics, 128(1), 1-15. https://doi.org/10.1016/j. jfineco.2018.01.003

18. Markowitz, H. (1952). Portfolio Selection. The Journal of Finance, 7(1), 77-91. https://doi. org/10.1111/j.1540-6261.1952. tb01525.x

19. Novy-Marx, R., \& Velikov, M. (2018). Betting Against Betting Against Beta (SSRN Working
Paper No. 3300965). https://doi. org/10.2139/SSRN.3300965

20. Peswani, S. G. (2017). Returns to Low-Risk Investment Strategy. Applied Finance Letters, 6(1), 2-15 https://doi.org/10.24135/afl. v6i01.65

21. Reserve Bank of India. (n.d.). Official site. Retrieved from https:// www.rbi.org.in/

22. Sharpe, W. (1964). Capital Asset Prices: A Theory of Market Equilibrium Under Conditions of Risk. Journal of Finance, 19(3), 425-442. https://doi. org/10.1111/j.1540-6261.1964. tb02865.x

23. Stambaugh, R., Jianfeng, Y., \& Yu Yuan. (2015). Arbitrage Asymmetry and the Idiosyncratic Volatility Puzzle. Journal of Finance, 70(5), 1903-1948. https://doi. org/10.1111/jofi.12286

24. Vasicek, O. (1973). A Note on Using Cross-Sectional Information in Bayesian Estimation of Security Betas. Journal of Finance, 28(5), 1233-1239. https://doi. org/10.1111/j.1540-6261.1973. tb01452.x

\section{APPENDIX A}

Table A1. Betting against volatility (BAV)

Source: Author's calculations.

\begin{tabular}{|c|c|c|c|c|c|c|}
\hline Return analysis & BAV 1 & BAV 2 & BAV 3 & BAV 4 & BAV 5 & BAV \\
\hline Excess returns & -0.89 & 0.74 & 0.16 & 1.33 & 0.81 & 0.57 \\
\hline CAPM alpha & 0.09 & 1.21 & 0.64 & 1.70 & 1.20 & 0.97 \\
\hline t-stat & 0.12 & 2.85 & 1.55 & 5.14 & 3.19 & 2.72 \\
\hline MKT & -0.32 & -0.37 & -0.37 & -0.34 & -0.31 & -0.34 \\
\hline t-stat & -3.35 & -6.40 & -6.65 & -7.58 & -6.13 & -7.11 \\
\hline Ex-post beta & -0.32 & -0.37 & -0.37 & -0.34 & -0.31 & -0.34 \\
\hline $\mathrm{R}^{2}$ & 0.05 & 0.16 & 0.17 & 0.20 & 0.14 & 0.18 \\
\hline Sharpe ratio & -0.27 & 0.39 & 0.08 & 0.90 & 0.49 & 0.35 \\
\hline 3F alpha & -0.33 & 1.17 & 0.55 & 1.62 & 1.09 & 1.12 \\
\hline t-stat & -0.40 & 3.14 & 1.35 & 5.43 & 3.08 & 3.66 \\
\hline MKT & -0.15 & -0.23 & -0.29 & -0.27 & -0.26 & -0.23 \\
\hline t-stat & -1.26 & -4.34 & -4.81 & -6.23 & -5.17 & -5.15 \\
\hline SML & -0.92 & -0.61 & -0.48 & -0.47 & -0.55 & -0.58 \\
\hline t-stat & -4.53 & -6.72 & -4.82 & -6.46 & -6.35 & -7.76 \\
\hline VMG & -0.14 & -0.06 & -0.02 & 0.14 & 0.22 & 0.04 \\
\hline t-stat & -0.74 & -0.68 & -0.21 & 2.00 & 2.74 & 0.51 \\
\hline $\mathrm{R}^{2}$ & 0.18 & 0.38 & 0.28 & 0.34 & 0.28 & 0.41 \\
\hline
\end{tabular}

Note: Bold indicates $5 \%$ statistical significance.

Table A1 reports the performance of the BAV factor in each volatility quintile and the equal-weighted average of these factors, which is the main BAV factor. Alphas are the intercept in a regression of monthly excess return against the explanatory variables - MKT, SML and VMG. Alphas and Sharpe ratios are reported on a monthly and annualized basis, respectively. $t$-statistics are shown below the coefficient estimates. 


\section{APPENDIX B}

Table B1. LMAX and SMAX based on yearly look-back periods, namely LMAX1Y and SMAX1Y

\begin{tabular}{|c|c|c|c|c|c|c|}
\hline Key metrics & SMAX1Y & SMAX1Y & SMAX1Y & LMAX1Y & LMAX1Y & LMAX1Y \\
\hline Alpha & -0.93 & -0.82 & -0.39 & 0.60 & 0.57 & -0.05 \\
\hline t-stat & -3.62 & -3.36 & -1.71 & 2.28 & 2.15 & -0.22 \\
\hline MKT & 0.27 & 0.25 & 0.23 & -0.58 & -0.57 & -0.55 \\
\hline t-stat & 7.17 & 7.18 & 7.34 & -15.07 & -14.95 & -17.30 \\
\hline SML & -0.05 & -0.05 & 0.02 & -0.39 & -0.39 & -0.49 \\
\hline t-stat & -0.83 & -0.86 & 0.28 & -6.09 & -6.11 & -9.11 \\
\hline VMG & -0.07 & -0.07 & -0.12 & 0.06 & 0.06 & 0.12 \\
\hline t-stat & -1.16 & -1.33 & -2.30 & 0.98 & 1.01 & 2.45 \\
\hline ST_ReV & - & 0.28 & 0.21 & - & -0.08 & 0.01 \\
\hline t-stat & - & 5.32 & 4.48 & - & -1.49 & 0.12 \\
\hline $\mathrm{BAB}$ & - & - & -0.36 & - & - & 0.52 \\
\hline t-stat & - & - & -7.03 & - & - & 10.31 \\
\hline Sharpe ratio & -0.71 & -0.71 & -0.71 & -0.06 & -0.06 & -0.06 \\
\hline $\mathrm{R}^{2}$ & 0.19 & 0.28 & 0.41 & 0.63 & 0.63 & 0.75 \\
\hline
\end{tabular}

Note: Bold indicates $5 \%$ statistical significance.

Table B1 reports alphas from the regression of LMAX1Y and SMAX1Y factors on the explanatory variables - MKT, SML, VMG, ST_Rev, and BAB. Alphas and Sharpe ratios are reported on a monthly and annualized basis, respectively. t-statistics are shown below the coefficient estimates.

\section{APPENDIX C}

Table C1. Performance marathon among factors constructed using the rank-weighted method

Source: Author's calculations.

\begin{tabular}{|c|c|c|c|c|c|c|c|c|c|c|c|c|}
\hline Key metrics & BAB & BAB & BAC & BAC & BAV & BAV & LMAX & LMAX & SMAX & SMAX & IVOL & IVOL \\
\hline Alpha & 1.43 & 0.65 & 1.17 & 0.82 & 1.37 & 0.58 & 0.95 & 0.34 & -0.08 & -0.06 & 1.29 & 0.63 \\
\hline t-stat & 5.19 & 2.78 & 4.68 & 3.26 & 5.42 & 2.88 & 4.80 & 2.02 & -0.71 & -0.55 & 5.93 & 3.36 \\
\hline MKT & -0.05 & 0.13 & 0.00 & 0.08 & -0.16 & 0.02 & -0.21 & -0.19 & -0.01 & -0.01 & -0.22 & -0.19 \\
\hline t-stat & -1.28 & 3.55 & -0.10 & 1.97 & -4.36 & 0.72 & -7.65 & -8.49 & -0.51 & -0.54 & -7.08 & -7.76 \\
\hline SML & 0.23 & 0.35 & 0.69 & 0.74 & -0.48 & -0.36 & -0.15 & -0.24 & 0.02 & 0.03 & -0.21 & -0.31 \\
\hline t-stat & 4.38 & 7.97 & 14.54 & 15.80 & -10.04 & -9.54 & -3.89 & -7.66 & 1.14 & 1.19 & -5.05 & -8.98 \\
\hline VMG & -0.26 & -0.20 & -0.15 & -0.13 & -0.23 & -0.18 & -0.07 & 0.04 & 0.08 & 0.08 & -0.08 & 0.04 \\
\hline t-stat & -3.90 & -3.74 & -2.50 & -2.15 & -3.85 & -3.78 & -1.47 & 1.00 & 2.97 & 2.78 & -1.58 & 0.84 \\
\hline ST_Rev & -0.23 & -0.48 & -0.23 & -0.34 & -0.11 & -0.36 & 0.31 & 0.40 & 0.69 & 0.69 & 0.03 & 0.13 \\
\hline t-stat & -3.65 & -8.61 & -3.99 & -5.66 & -1.93 & -7.60 & 6.83 & 10.78 & 27.66 & 26.73 & 0.58 & 3.25 \\
\hline BAB & - & - & - & - & - & - & - & 0.42 & - & -0.01 & - & 0.46 \\
\hline t-stat & - & - & - & - & - & - & - & 10.80 & - & -0.36 & - & 10.68 \\
\hline LMAX & - & 0.82 & - & 0.37 & - & 0.83 & - & - & - & - & - & - \\
\hline t-stat & - & 10.80 & - & 4.49 & - & 12.66 & - & - & - & - & - & - \\
\hline Sharpe ratio & 0.95 & 0.95 & 0.79 & 0.79 & 0.35 & 0.35 & 0.74 & 0.74 & 0.33 & 0.33 & 0.79 & 0.79 \\
\hline$R^{2}$ & 0.17 & 0.46 & 0.58 & 0.61 & 0.61 & 0.77 & 0.43 & 0.63 & 0.80 & 0.80 & 0.41 & 0.61 \\
\hline
\end{tabular}

Note: Bold indicates $5 \%$ statistical significance.

Table $\mathrm{C} 1$ reports the regression results of all factors constructed using a rank-weighted methodology. Alphas and Sharpe ratios are reported on monthly and annualized basis, respectively. t-statistics are shown below the coefficient estimates. 